\title{
Use of native Y-saphenous vein graft in multi-vessel coronary bypass surgery
}

\author{
Sinan Göçer ${ }^{1}$, Mehmet Karaçalilar ${ }^{2}$, Süleyman Yazici ${ }^{3}$, Cemalettin Aydin ${ }^{4}$ \\ ${ }^{1}$ MEDICAL SCHOOL OF BAHÇESSEHIR UNIVERSITY, DEPARTMENT OF CARDIOVASCULAR SURGERY, ISTANBUL, TURKEY \\ ${ }^{2}$ BATMAN STATE HOSPITAL, DEPARTMENT OF CARDIOVASCULAR SURGERY, BATMAN, TURKEY \\ ${ }^{3}$ MEDICAL SCHOOL OF DEMIROĞLU BILIM UNIVERSITY, DEPARTMENT OF CARDIOVASCULAR SURGERY, ISTANBUL, TURKEY \\ ${ }^{4}$ BEZMIALEM VAKIF UNIVERSITY, DEPARTMENT OF CARDIOVASCULAR SURGERY, ISTANBUL,TURKEY
}

\section{ABSTRACT}

Objective. Demonstration of the advantages of using the natural $\mathrm{Y}$ shaped form of saphenous vein graft, which is the most preferred coronary bypass graft after internal thoracic artery (ITA). Methods. 32 patients with coronary artery disease who underwent coronary bypass grafting (CABG) with 3 or more distal anastomoses between January 2014 and January 2018 were included in the study. The natural Y saphenous vein grafts were used in these operations beside of LIMA-LAD anastomosis. Patients have been evaluated in terms of early and short-term survival, early cardiac events, the need for reoperation, and the need for percutaneous transluminal coronary angioplasty (PTCA). All patients were followed up directly by outpatient examination or telephone consultation. Results. New cardiac events, reoperation and death were not seen in the early postoperative period. Coronary angiography performed in 3 patients due to angina in the second and third years revealed that all anastomoses of $y$-saphenous grafts were open. No mortality was observed in the patients who were followed remotely. The duration of operation and the duration of cardiopulmonary bypass resulted in a reduction in the number of proximal anastomoses and the time by about 10 to 15 minutes. The incision in the saphenous leg was about $10 \mathrm{~cm}$ shorter for each anastomosis. Conclusion. The natural shaped Y saphenous vein can be used safely in multi vessel coronary artery disease (CAD) patients for reducing the surgical trauma.
Category: Original Research Paper

Received: July 14, 2020

Accepted: September 10, 2020

Keywords:

Coronary artery disease, CABG surgery, natural Y shaped saphenous vein

\section{*Corresponding author:}

Süleyman Yazici,

Medical School of Demiroğlu Bilim University, Department of Cardiovascular Surgery, İstanbul, Turkey E-mail: drsuleymanyazici@gmail.com

\section{Introduction}

Due to coronary artery disease, millions of people undergo coronary artery bypass surgery $(\mathrm{CABG})$ every year in the world [1]. The choice of graft and anastomosis strategy determines the success and longterm results of CABG operation [2]. Even though the most desired surgical strategy which has the best results is represented by full myocardial revascularization with arterial grafts, saphenous vein is still the second most preferred surgical graft after internal thoracic artery (ITA) [3].

Besides the classical technique, single graft single anastomosis, various graft and anastomotic techniques have been proposed for economic graft usage, shortening the duration and decreasing the trauma of CABG for multi- vessel CAD patients. These are bilateral ITA, sequential anastomosis with single graft, arterial or venous composite grafts and natural shaped $\mathrm{Y}$ saphenous grafts [4].

During saphenous vein graft harvesting, the $\mathrm{Y}$ shaped saphenous vein is encountered nearly $50 \%$ of patients [5]. Usage of natural $\mathrm{Y}$ shaped saphenous grafts decrease the amount of proximal anastomosis, manipulation of ascending aorta and the operation time.

And also using of one graft for more than one anastomosis will reduce the saphenous leg incisions. As the results of all these aspects, the trauma of operation will be fewer. 
In our study, we share our early and mid-term results of natural Y saphenous grafts using complementary to LIMALAD anastomosis at multi-vessel CAD patients.

\section{Materials and Methods}

Thirty-two patients with coronary artery disease who underwent CABG with 3 or more distal anastomoses (between January 2014 and January 2018) were included in the study. Natural Y saphenous vein grafts were used in these operations beside of LIMA-LAD anastomoses. The patients who benefited from this $\mathrm{Y}$ saphenous technique were chosen randomly. They did not have any specific feature except having natural $\mathrm{Y}$ shaped saphenous vein. Patients have been evaluated in terms of early and shortterm survival, early cardiac events, the need for reoperation, and the need for percutaneous transluminal coronary angioplasty. All patients were followed up directly by outpatient examination or telephone consultation.

Before the operation, detailed information about surgery was given to the patients and acceptance form was signed by each patient.

\section{Operation technique}

After median sternotomy, saphenous vein and ITA were harvested. The saphenous vein was harvested from the ankle up toward the knee. Thigh veins were seldom used. Branches of Y saphenous vein were harvested at least $2 \mathrm{~cm}$ long. All cases were performed under cardiopulmonary bypass. The distal anastomoses of the Ygraft were performed on the diagonal arteries, diagonal and obtuse marginal arteries or two obtuse marginal arteries Figure 1. All proximal anastomoses were performed on the ascending aorta.

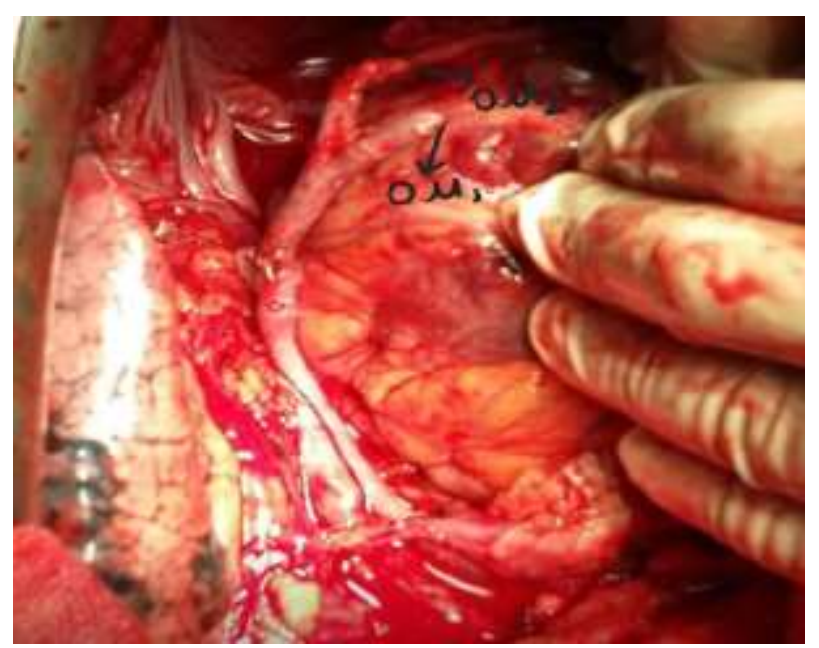

Figure 1. The distal anastomoses of the Y-graft (OM1 and OM2 - obtuse margin 1 and obtuse margin 2).

\section{Results}

New cardiac events, reoperation and death were not seen in the early postoperative period.

Coronary angiography performed in 3 patients due to angina in the second and third years revealed that all anastomoses of y-saphenous grafts were open (Figure 2). No mortality was observed in the patients who were followed remotely. The duration of operation and the duration of cardiopulmonary bypass resulted in a reduction in the number of proximal anastomoses and the time by about 10 to 15 minutes. The incision in the saphenous leg was about $10 \mathrm{~cm}$ shorter for each anastomosis.

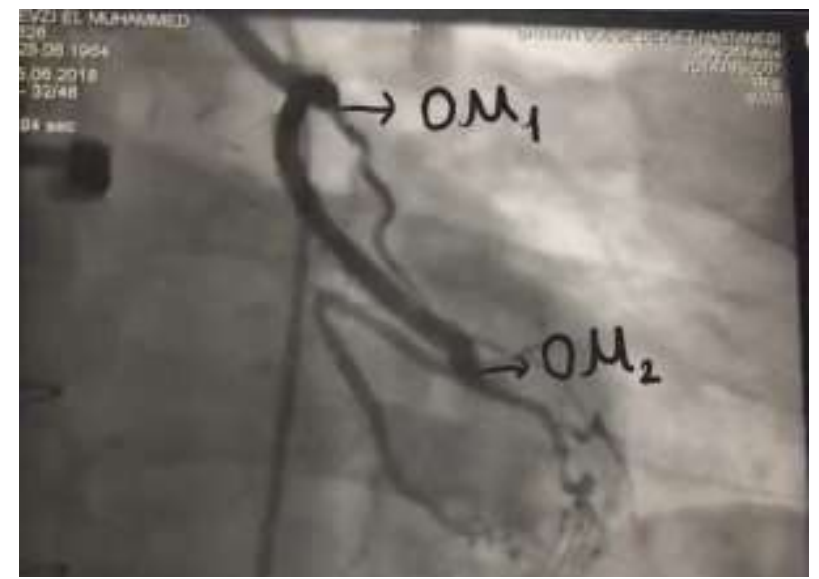

Figure 2. Coronary angiography revealed that anastomoses of $\mathrm{y}$-saphenous grafts were open (OM1 and OM2 - obtuse margin 1 and obtuse margin 2).

\section{Discussions}

According to the statistics ischemic heart disease have remained the leading causes of death globally for several years [6]. Every year millions of people are undergoing CABG surgery all around the world [1]. In treatment of multi-vessel CAD with or without LMCA, CABG comes before PCI in terms of less re-revascularization and long survival rates [7].

Main strategy of CABG is full myocardial revascularization [8]. Because of their long-term patency rates, internal thoracic arteries (ITA) are most effective grafts in this strategy [9]. However, the saphenous vein is still the second most preferable graft in CABG surgery [3]. In literature, there is some studies that showed superiority of saphenous grafts to radial artery especially in elderly patients [10].

Many configurations and surgical techniques in anastomosis have been proposed to improve surgical treatment, including full arterial complete myocardial revascularization, bilateral ITA with or without radial artery, single graft with sequential anastomosis, composite 
grafts with artery or veins and natural shaped Y saphenous grafts [4].

During harvesting, $\mathrm{Y}$ shaped saphenous grafts are encountered occasionally [5]. Using saphenous vein with this state for multiple anastomosis will reduce saphenous leg incision through the economic graft usage. In Y shaped saphenous vein, branches should be at least 2 to $3 \mathrm{~cm}$ long and $80 \%$ width of main trunk [4]. Although the single graft sequential anastomosis technique is more common and used technique, both anastomoses in the Y saphenous graft have the comfort of being end to side.

In CABG surgery, complications due to ascending aorta manipulations are neurological events resulting from calcium and cholesterol debris embolism [11,12]. And inflammation as a result of CPB times have serious side effects over renal and pulmonary systems that causing prolonged intensive care unit and hospital stay or even mortality especially in elderly patients $[13,14]$. The natural $\mathrm{Y}$ shaped saphenous graft usage will reduce number of proximal anastomoses, manipulation of ascending aorta and shorten cardiopulmonary perfusion and operation time. These advantages of $\mathrm{Y}$ saphenous vein usage will reduce surgical trauma and complication risks.

Composite vein and artery grafts are used for multiple anastomoses in CABG surgery [15]. Y shaped saphenous veins have more physiological flow when compared to composite vein grafts [4]. In addition, preparation of composite graft extends the operation time and also increases the possibility of bleeding due to additional anastomosis.

The disadvantage of $\mathrm{Y}$ saphenous vein that the thrombosis on main proximal anastomose or a stenosis before the first branch will endanger all target coronary arteries [16]. But this risk is available for saphenous grafts using for sequential anastomoses. We do not have such problems in our patients in post op early, short and midterm periods.

\section{Conclusions}

Natural shaped Y saphenous vein can be used safely in multi vessel CAD patients for reducing the surgical trauma through fewer proximal anastomosis and manipulation of ascending aorta, short operational time and less incision of saphenous leg.

\section{Conflict of interest disclosure}

There are no known conflicts of interest in the publication of this article. The manuscript was read and approved by all authors.

\section{Compliance with ethical standards}

Any aspect of the work covered in this manuscript has been conducted with the ethical approval of all relevant bodies and that such approvals are acknowledged within the manuscript.

\section{References}

1. Rich JB, Fonner CE, Quader MA, Ailawadi G, Speir AM. Impact of Regional Collaboration on Quality Improvement and Associated Cost Savings in Coronary Artery Bypass Grafting. Ann Thorac Surg. 2018;106(2):454-459.

doi:10.1016/j.athoracsur.2018.02.055

2. Windecker S, Kolh P, et al. 2014 ESC/EACTS Guidelines on myocardial revascularization: The Task Force on Myocardial Revascularization of the European Society of Cardiology (ESC) and the European Association for Cardio-Thoracic Surgery (EACTS) Developed with the special contribution of the European Association of Percutaneous Cardiovascular Interventions (EAPCI). Eur Heart J. 2014;35(37):2541-2619. doi:10.1093/eurheartj/ehu278

3. Hayward PA, Buxton BF. Contemporary coronary graft patency: 5-year observational data from a randomized trial of conduits. Ann Thorac Surg. 2007;84(3):795799. doi:10.1016/j.athoracsur.2007.04.028

4. Yu S, Zhang W, Wang L, et al. Effectiveness of Saphenous Vein Y-Grafts in Patients Undergoing OffPump Complete Myocardial Revascularization. Med Sci Monit. 2019;25:598-604. Published 2019 Jan 21. doi:10.12659/MSM.911981

5. Yeh TJ, Heidary D, Shelton L. Y-grafts and sequential grafts in coronary bypass surgery: a critical evaluation of patency rates. Ann Thorac Surg. 1979;27(5):409412. doi:10.1016/s0003-4975(10)63336-x

6. Roth GA, Johnson C, Abajobir A, et al. Global, Regional, and National Burden of Cardiovascular Diseases for 10 Causes, 1990 to 2015. J Am Coll Cardiol. 2017;70(1):125. doi:10.1016/j.jacc.2017.04.052

7. Hillis LD, Smith PK, Anderson JL, et al. 2011 ACCF/AHA guideline for coronary artery bypass graft surgery: executive summary: a report of the American College of Cardiology Foundation/American Heart Association Task Force on Practice Guidelines. $J$ Thorac Cardiovasc Surg. 2012;143(1):4-34. doi: 10.1016/j.jtcvs.2011.10.015

8. Li J, Schindler TH, Qiao S, et al. Impact of incomplete revascularization of coronary artery disease on longterm cardiac outcomes. Retrospective comparison of angiographic and myocardial perfusion imaging 
criteria for completeness. $J$ Nucl Cardiol. 2016;23(3):546-555. doi:10.1007/s12350-015-0109-4

9. Cameron A, Davis KB, Green G, Schaff HV. Coronary bypass surgery with internal-thoracic-artery grafts-effects on survival over a 15-year period. $N$ Engl J Med. 1996;334(4):216-219.

doi:10.1056/NEJM199601253340402

10. Hayward PA, Buxton BF. Contemporary coronary graft patency: 5-year observational data from a randomized trial of conduits. Ann Thorac Surg. 2007;84(3):795799. doi:10.1016/j.athoracsur.2007.04.028

11. Cropsey C, Kennedy J, Han J, Pandharipande P. Cognitive Dysfunction, Delirium, and Stroke in Cardiac Surgery Patients. Semin Cardiothorac Vasc Anesth. 2015;19(4):309-317. doi:10.1177/1089253215570062

12. Lorusso R, Moscarelli M, Di Franco A, et al. Association Between Coronary Artery Bypass Surgical Techniques and Postoperative Stroke. $J$ Am Heart Assoc. 2019;8(24):e013650. doi:10.1161/JAHA.119.013650

13. Aljure OD, Fabbro M 2nd. Cardiopulmonary Bypass and Inflammation: The Hidden Enemy. $J$ Cardiothorac Vasc Anesth. 2019;33(2):346-347. doi: 10.1053/j.jvca.2018.05.030

14. Bronicki RA, Hall M. Cardiopulmonary BypassInduced Inflammatory Response: Pathophysiology and Treatment. Pediatr Crit Care Med. 2016;17(8 Suppl 1):S272-S278. doi:10.1097/PCC.0000000000000759

15. Hulusi M, Basaran M, Ugurlucan M, Kocailik A, Basaran EK. Coronary artery bypass grafting with Ysaphenous vein grafts. Angiology. 2009;60(6):668-675. doi:10.1177/0003319709334261

16. Lusini M, Pollari F, Sedati P, Chello M, Covino E. Natural "Y" venous graft for coronary revascularization. Tex Heart Inst J. 2013;40(5):628629. 